\title{
New impact factor and many new studies
}

Our new impact factor has increased to 1.596, and our five-year impact factor has increased to 1.623 as is evident from this issue of our journal. This gives us the confidence and motivation to perform better. It goes without saying that we could not have achieved this result without all of you. We would like to express our deep gratitude to all our editorial board members, authors, reviewers, the publisher of the journal, and the directors of the Turkish Society of Cardiology (the owner of the journal). We hope that our hard work will enable us to reach more significant goals together.

As a new marker for the early diagnosis of acute myocardial infarction, Etem Önalan et al. from Turkey present their findings in their paper titled, "Common single nucleotide polymorphisms in the FNDC5 gene and serum irisin levels in acute myocardial infarction."

Genç Yavuz et al. from Turkey investigated the predictive power of serum corin levels in distinguishing between hypertensive urgency and hypertensive emergency in patients with hypertensive crisis admitted to the emergency department. This is an important point during emergency.

The pulmonary embolism (PE) severity index (PESI) predicts long-term mortality after acute PE. Sandal et al. (Turkey) have aimed to evaluate the accuracy of original and simplified PESI to predict all-cause mortality after 30 days of acute PE diagnosis up to five years within consecutive sub-periods. This manuscript will shed light on the long-term mortality factors in patients with PE.

Does increased interleukin (IL)-6 levels predict right ventricular systolic impairment in patients hospitalized with coronavirus disease 2019? Erdoğan et al. from Turkey attempt to answer that question in their paper.

"Left ventricular characteristics of patients with non-compaction phenotype and with good ejection fraction measured with cardiac magnetic resonance" is a remarkable paper by Kiss et al. from Hungary. They also investigated the left ventricular trabeculated muscle mass cut-off in male and female patients with left ventricular non-compaction cardiomyopathy.

The study by Akın and Bilge from Turkey is the first in the literature to investigate frontal QRS-T angle and the severity of coronary artery disease in patients with non-diabetic stable angina pectoris, and they claim to have good results.

Standardized criteria for structural valve deterioration (SVD) and bioprosthetic valve failure (BVF) have recently been defined. Only a limited number of studies have evaluated the long-term durability of transcatheter aortic valve implantation(TAVI) according to these new criteria. Şentürk et al. from Turkey aimed to analyze the durability of TAVI after five years and report the frequency of SVD and BVF. The findings of this study will add value to the literature on this issue.

This issue includes interesting case reports, letters, e-page originals.

I hope this new issue will be of interest to our readers.

\section{Prof. Dr. Çetin Erol \\ Editor-in-Chief \\ Ankara-Turkey}

Address for Correspondence: Prof. Dr. Çetin Erol, Ankara Üniversitesi Tıp Fakültesi, İbn-i Sina Hastanesi, Kardiyoloji Anabilim Dalı, Ankara-Türkiye

Phone: +90 3123103333 /27 79 E-mail: ctnerol@yahoo.com 